\title{
RECURSOS DE LA EDUCACIÓN FAMILIAR PARA DAR SENTIDO A LA GLOBALIZACIÓN ${ }^{1}$
}

\author{
Ana Teresa López de Llergo \\ Luz María Cruz de Galindo
}

\section{RESUMEN}

Paradójicamente, en un mundo donde las definiciones conceptuales no importan, se consideran anacrónicas y se evalúan poco, encontramos términos acuñados, generalizados y casi impuestos. Quien no los usa está fuera de lugar, se rezaga e incluso tiene dificultades para integrarse en algún grupo social. Se emplean y acuñan nociones muy antiguas con palabras nuevas, nociones de las que siempre se ha hablado y parece que hasta ahora se descubren, aunque se ignore la extensión de su significado. Esto sucede con el término globalización, mencionado una y otra vez, casi con la única finalidad de estar "al día".

El fenómeno de la globalización se ha presentado en muy distintas formas a lo largo de la historia. Por ejemplo, en el liderazgo de Napoleón Bonaparte; en el sueño unionista de Simón Bolívar o de Erasmo de Rotterdam. Con siglos de distancia, está latente el mismo fenómeno, pues se relaciona con cuestiones antropológicas en donde el tiempo y el espacio no son determinantes.

La globalización se ha convertido en sinónimo de universalidad y ha polarizado opiniones. Algunos -llamados globalifóbicos-

\footnotetext{
${ }^{1}$ Ponencia presentada para el $13^{\circ}$ Congreso Anual de Socio-Economía en la Universidad de Amsterdam, 28 de junio a 1ํㅡㄹ julio de 2001.
} 
la temen, pues piensan que por ella se pierde la identidad de lo regional, de lo propio. Otros - globalifílicos- consideran que es panacea y meta por alcanzar a como dé lugar. Con nuestro trabajo pretendemos resaltar conductas familiares sostenibles para asumir de manera adecuada un fenómeno que ha tomado carta de ciudadanía.

\section{QUÉ ENTENDEMOS POR EDUCACIÓN FAMILIAR}

La educación es un proceso vitalicio de mejora que permite al ser humano el desarrollo de sus facultades corporales y espirituales para el cumplimiento de sus fines. Como actividad del educador, se trata de una ayuda que busca el armónico desarrollo del educando para crecer juntos. El destinatario de la acción educativa, de acuerdo con su edad y situación personal, necesita asumir una actitud protagónica: querer educarse y poner los medios para lograrlo.

Los ámbitos educativos más relevantes son la familia, la institución escolar y el entorno sociocultural. En la primera es donde mejor puede brindarse el conocimiento amoroso que facilita una educación personalizada -con sentido comunitariopropia de la dignidad del ser humano.

Entre las principales adquisiciones familiares encontramos algunos elementos indispensables para la vida social, la comunicación y el lenguaje; las primeras habilidades motrices; los elementos cognitivos, fundamento de la vida intelectual; el desarrollo de la afectividad que puede favorecer el sentimiento de confianza básica y la afirmación y autonomía personal ${ }^{2}$. Esto es posible porque en la familia hay una extraordinaria unidad en la pluralidad. Integrada por personas de diferente edad y sexo, en su seno se realizan las actividades más diversas que, si se saben aprovechar, pueden ser altamente educativas.

${ }^{2}$ Cfr. GARCÍA HOZ, Víctor., La educación personalizada en la familia., Tratado de educación personalizada., Tomo 7., p.17. 
La familia es a la vez fuente y sujeto de educación, y necesita de otras instancias para cumplir bien sus tareas. No se pretende que los padres abandonen su papel como primeros responsables de la educación de sus hijos, sino que lo asuman de una manera más consciente, y que deleguen en otros sólo lo delegable.

El mejor medio de educación de padres e hijos es la misma vida de familia, con un ambiente que favorezca el diálogo y la participación de cada uno. Son los padres quienes han de dar el tono a la vida en común; si entre ellos existe armonía y espíritu de servicio, los hijos se irán formando la idea de una humanidad ordenada, pacífica, constructiva y no la de una realidad distorsionada, agresiva, contradictoria.

Aquí aparece la educación familiar como actividad profesional para ayudar a los padres a desempeñar su tarea con eficiencia dentro de lo espontáneo. Los progenitores, con el apoyo de una reflexión seria y sistemática, y con la ayuda de la experiencia propia y ajena, pueden mejorar sus procedimientos educativos. Sin embargo, los programas de educación familiar y sus enfoques pedagógicos son, aunque valiosos, limitados, pues no pueden captar toda la riqueza de los aspectos académicos, sociales, culturales, etcétera, que encierra la vida misma.

No siempre es fácil encontrar en los textos de educación familiar o en los temas de escuelas para padres, la relación con el modo cotidiano de proceder de los adultos ante los aspectos educativos. A ellos les interesan los temas reales y el análisis de la propia experiencia; por eso, la educación en el ámbito familiar es una dimensión totalmente cercana y accesible a los padres. Sin embargo, conviene que el profesional tenga presente que las diferencias individuales se incrementan con la edad y la autonomía de los hijos, pues se manejan en un campo legítimo donde afianzan sus criterios. Por eso, la educación familiar supone que cada familia es un caso que sugiere a otras modos de proceder, pero no es pauta para establecer metodologías rígidas. 
La originalidad de la educación familiar que imparten los padres radica en dimensiones profundas, relacionadas con la misión formadora del ser humano. Sus objetivos son más dinámicos y vivos que las mismas sentencias en las que pueden, literalmente, encerrarse. Por ello, sólo los padres, con el abnegado trabajo cotidiano y con disponibilidad -ingredientes esenciales del verdadero amor- pueden asimilar, interpretar y personalizar los objetivos de la educación familiar, y hacerlos vida en sí mismos y en cada hijo ${ }^{3}$.

Hoy, la figura del educador familiar adquiere una importancia especial por dos razones:

- La crisis de la institución familiar ha afectado a innumerables familias: las relaciones conyugales y paterno-filiales se encuentran gravemente deterioradas. Algunos padres han abandonado su protagonismo educativo y delegado lo indelegable en otras instituciones (escuela, clubes, etcétera). Existen familias terriblemente confundidas. Su deseo -a veces compulsivo e indiscriminado- de intergrarse a los vertiginosos cambios de nuestro mundo moderno, les ha hecho perder su propia identidad.

- La existencia de familias conscientes de su insustituible misión. Aquí el profesional ha de encauzar las posibilidades educativas del núcleo familiar para que responda adecuadamente a los retos contemporáneos.

La institución familiar debe dar el tono a la vida social y no viceversa. La sociedad del mañana será lo que sean sus familias, porque en ellas se gesta el futuro de las naciones.

\section{EDUCACIÓN FAMILIAR COMO FIJADORA DE IDENTIDAD}

La familia es el espacio educativo por excelencia y el ambiente más propicio para el desarrollo personal y el descubrimiento

${ }^{3}$ Cfr. CHICO GONZÁLEZ, P., "Objetivos de la educación familiar para cada edad de los hijos", en La educación personalizada en la familia., p.179. 
de la propia identidad. Es la que primero influye -cronológicamente hablando- y la que deja una huella más honda en la persona. Huella positiva cuando hay amor y aceptación incondicional que no excluye malos entendidos, faltas de afinidad, distanciamientos, etcétera. Huella negativa cuando lo propio de la familia se corrompe y hay franco rechazo, abandono o indiferencia. En el núcleo familiar es posible que las personas se conozcan a sí mismas de una manera objetiva, pues los parientes cercanos ayudan a hacerlo, por la convivencia tan íntima y cotidiana, que permite la necesaria confrontación con uno mismo y la aceptación de lo que cada cual es.

Al reflexionar sobre la propia identidad es posible la autoevaluación y la autonomía personal, fruto del autoconocimiento. También puede favorecer la buena convivencia con los demás y el realismo necesario para estar bien ubicados dentro del grupo y para organizar actividades cotidianas. La identidad se expresa de manera espontánea en una dinámica social. Cuando esta identidad se asume adecuadamente, nos ayuda a regular las agresiones, señala los límites del dominio territorial (ya que además de la ubicación grupal existe la espacio-temporal, que garantiza el arraigo y la seguridad de una propiedad defendible) y también los límites de la propia autonomía.

En el núcleo familiar se plasma la identidad de quienes lo constituyen. No sólo la personal sino también la colectiva, que es el sentido de pertenencia a ese determinado grupo con su correspondiente estatus sociocultural.

Por ejemplo, normalmente la vivienda que se elige o se adapta responde al modo de ser de sus habitantes: ellos la personalizan mediante cierta decoración y revestimiento. Así, va fortaleciéndose, naturalmente, el proceso de identificación individual y grupal. Esta personalización no sólo expresa los gustos e intereses de quienes habitan una casa, sino también los valores de la cultura y sociedad a la que pertenecen. La morada delimita una realidad sutil pero mucho más rica, el 
hogar, que incluye la construcción y lo que hay en ella y en su entorno, las personas que la habitan, y la satisfacción que todo esto aporta.

El hogar es entonces la conexión primaria entre el ser humano y el resto del mundo, porque otorga significado e identidad a cada existencia, estructura las relaciones sociales, proporciona una habitación para las actividades cotidianas, es el centro de una serie de actos regulares y predecibles, y desencadena muchos de los recuerdos que configuran el pasado. Todo eso forma un vínculo psicológico con el ambiente, vínculo que se hace extensivo al lugar geográfico donde se nace, al barrio, a los paisanos. Por analogía, la comunidad es el hogar de quienes la constituyen y también propicia la identidad personal, que incluye lo íntimo, y la identidad comunitaria que da un sentido de pertenencia, traducido en la nacionalidad y en el patriotismo.

El sentimiento de pertenencia es como una ampliación de uno mismo, como si se borraran los límites entre el yo y el ambiente. Y cuando se tiene arraigo y centralidad familiar aparecen círculos concéntricos de pertenencia. Por eso, con un apoyo sólido es posible estar bien globalizado, si no, se es presa de todos los vientos y no hay garantía de fidelidad.

Cuando la vida en sociedad no favorece el desarrollo de las facultades de la persona, surgen dos fenómenos característicos de nuestro mundo contemporáneo: el desarraigo existencial de individuos y grupos que parecen no tener ningún sentido para sus vidas, y el estatismo totalitario que quiere adjudicarse las decisiones que cada uno, solo o en grupo, debe asumir.

Arraigo y continuidad son aspiraciones propias de nuestra condición de personas, y guardan una estrecha relación con el ámbito espacio-temporal. El arraigo es tal vez la más importante y la más desconocida necesidad del alma humana. La persona tiene una raíz por su participación real, activa y natural en la existencia de una colectividad que conserva ciertos tesoros del pasado y ciertos presentimientos del porvenir. Participación 
natural producida automáticamente por el lugar, nacimiento, profesión, contorno. Cada ser humano tiene necesidad de múltiples raíces. Tiene precisión de recibir casi la totalidad de su vida moral, intelectual, espiritual, por intermedio de los ambientes de los que naturalmente forma parte ${ }^{4}$.

Debido al desarraigo existencial, el sujeto pierde el bien más profundo: el lazo misterioso y cordial con las cosas de su mundo que son tan valiosas para él y que contribuyen a dar sentido a su vida ${ }^{5}$. Sin embargo se requiere de cierto equilibrio, pues cuando el arraigo se vuelve apego, hay consecuencias negativas para la existencia de una cultura global. El hombre sin raíces puede ser víctima de la masificación, que promueve la existencia de una igualdad en la mediocridad. Quizá la principal causa del gregarismo masificante sea la pérdida de interioridad, el vivir proyectados hacia afuera y olvidar el sabio consejo socrático. La falta de vida interior, la despersonalización, convierte al hombre en presa fácil de un poder estatal totalitario y opresivo.

\section{PRIMERA SOCIALIZACIÓN DE LA PERSONA, REQUISITO DE UNA SOCIEDAD GLOBAL}

Cuando la familia es sólida y funcional, sus miembros están mejor preparados para integrarse en sociedades más amplias. En un buen grupo familiar aparecen los grados jerárquicos armónicamente repartidos, y por lo general no resultan gravosos. Si la autoridad -paterna, materna o fraternal (cuando los hijos van siendo mayores)- se ejerce con espíritu de servicio, se convierte en un excelente medio para educar en la obediencia y en la participación, virtudes sociales fundamentales.

\footnotetext{
${ }^{4}$ Cfr. WEIL, Simone., "Le déracinement", en Le enracinement, cit. p.45, en VALLET DE GOYTISOLO, J., Sociedad de masas y derecho., p.110.

5 Cfr. GAMBRA CIUDAD, Rafael., El silencio de Dios., Editorial Prensa Española., Madrid., 1969., p.78, en VALLET DE GOYTISOLO, J., op.cit., p.112.
} 
José Pérez Adán señala que las responsabilidades colectivas -asunto tan defendido por los comunitaristas (Etzioni) y otros promotores de la familia- sólo pueden ser ejercidas si existen formas genuinas de compartir el poder. Sólo en la medida en que éste se ejerza con discrecionalidad, se propician actitudes responsables; lo que traducido al lenguaje de la cultura democrática contemporánea, se lee como que la participación es puerta de acceso a la corresponsabilidad. Por ello, el reconocimiento de la familia como sujeto soberano, abre camino hacia la reconciliación de todos los actores sociales en la tarea de construir una sociedad mejor ${ }^{6}$.

La familia -primera realidad social- ha de llevar a cabo acciones concretas que favorezcan el desarrollo de personas y comunidades. Esto se logrará si los padres ejercen un papel protagónico en la educación de sus hijos, y se preocupan por influir junto con ellos en el entorno, al cual perciben como prolongación de su núcleo familiar.

Si la familia ignora o desprecia el contexto sociocultural puede caer en actitudes individualistas impregnadas de autosuficiencia y falta de realismo. Pero si el desarrollo social descuida o ataca a las familias, es posible llegar a la masificación despersonalizadora.

Para evitarlo, las estructuras sociales necesitan favorecer el despliegue de la personalidad de todos y cada uno de los individuos que las integran. Asimismo, las familias y demás comunidades intermedias han de cumplir con su función educativa y socializante.

En el seno de la familia y de la escuela es viable educar a niños y jóvenes como futuros dirigentes sociales, que sepan hacer visibles las realidades de los valores y mostrarlas como realidades vitales; que no se dejen atrapar por frases estereotipadas y luchas ideológicas, sino que sean capaces de demostrar, con su vida, la solidez y operatividad de sus ideales y convicciones... 7. Esto será posible si familia y escuela se vinculan con grupos e instituciones de la comunidad.

${ }^{6}$ Cfr. Sociología., p.93.

${ }^{7}$ Cfr. MESSNER, J., La cuestión social., p.667. 
Es importante, además, que dentro de la influencia recíproca familia-sociedad, sea el grupo familiar quien marque la pauta para el estilo de vida comunitario, y no viceversa. La animación sociocultural, gestada, promovida y custodiada en el ámbito familiar, deberá expresarse de muy diversas maneras en la vida social. Por eso, saber convivir solidariamente es un objetivo prioritario en la educación. Este aprendizaje se da cuando en la familia se educa para ${ }^{8}$ :

- Equilibrar la educación de la intimidad y la educación de la apertura.

- Aprender a querer a los demás. Ejercitarse en el binomio dar-recibir.

- Saber informarse y participar, aprender a escuchar y a expresarse.

- Saber trabajar para una mejora personal, con afán de servicio.

De esta manera, la familia promoverá -implícitamente- a través de la animación sociocultural, un desarrollo comunitario. Para ello se requiere que en cada miembro del grupo social exista una conciencia cívica que haga de la participación ciudadana -para el logro del bien común- una posibilidad concreta y real.

\section{QUÉ ENTENDEMOS POR GLOBALIZACIÓN}

El concepto globalización ${ }^{9}$ pretende describir la realidad inmediata como una sociedad planetaria, más allá de fronteras, barreras arancelarias, diferencias étnicas, credos religiosos, ideologías políticas y condiciones socioeconómicas o culturales. Este fenómeno surge como consecuencia de la internacionalización cada vez más acentuada de los procesos económicos, los conflictos sociales y los fenómenos político-culturales.

En sus inicios, el término se empleó para describir los cambios en las economías nacionales -cada vez más integradas en

${ }^{8}$ Cfr. F. OTERO, Oliveros., ¿Qué es la orientación familiar?., p.96 y ss.

9 "Globalización". Enciclopedia ${ }^{\circledR}$ Microsoft ${ }^{\circledR}$ Encarta 2001., 1993-2000., Microsoft Corporation. 
sistemas sociales abiertos e interdependientes- sujetas a los efectos de la libertad de los mercados, las fluctuaciones monetarias y los movimientos especulativos del capital.

La caída del muro de Berlín constituyó el punto referencial de la institución de la economía de mercado. Así, la desaparición del bloque comunista impuso nuevas ideologías a escala mundial, planteamientos políticos de tercera vía, apuestas por la superación de los antagonismos tradicionales -como izquierdaderecha, Norte-Sur, tecnologizados y no tecnologizados-e, incluso, un afán de dar a la justicia dimensiones internacionales.

Los ámbitos de la realidad en los que mejor se refleja la globalización son la economía, la actividad laboral, la cultura, la innovación tecnológica y el ocio. En declaraciones a La Croix ${ }^{10}$, Amartya Sen, premio Nóbel de Economía en 1998, define la globalización como un proceso que se caracteriza por un mayor movimiento de bienes y de personas, de tecnología, de conocimiento.

Por eso, aunque sean muy variadas las manifestaciones culturales, los postulados de la acción política son casi iguales en todas partes: estabilidad de precios, equilibrio presupuestario, competitividad, privatización, liberación, etcétera. ¿Qué provoca esa similitud en los discursos políticos y en las directrices económicas en cualquier parte del planeta?, ¿por qué esa extraña impresión que a veces se percibe en los hoteles, por lo parecidos que éstos son, de que uno no ha cambiado de lugar cuando se encuentra en las antípodas de su sitio de residencia? Muchas personas coinciden en que la mundialización de los discursos es consecuencia de la globalización de los mercados ${ }^{11}$.

Debido al fenómeno de la globalización, en todos los países está creciendo un movimiento en favor de la presencia de un tribunal internacional para juzgar los delitos contra los

${ }^{10}$ París, 29 de junio de 2000.

${ }^{11}$ Cfr. MÁRQUEZ PIÑERO, Rafael., Derecho penal y globalización., p.XIII-XIV. 
derechos humanos, como el genocidio, el terrorismo y la persecución política, religiosa, étnica o social. Esto resulta muy significativo, pues es la manifestación externa del percibir el mundo como una aldea.

Para precisar conceptos acudiremos a Porfirio Muñoz Ledo, integrante del Centro Latinoamericano de la Gobalidad (CELAG), quien distingue entre globalidad y globalización. Desde su punto de vista, el primero es un fenómeno complejo y antiguo que aparece a finales del siglo XV y que ha tenido manifestaciones de una intensa dinámica a partir de la segunda guerra mundial. Por su parte, la globalización es, al mismo tiempo, un proceso y un conjunto de procesos de internacionalización social, económica y política, y comprende, por otro lado, los fenómenos de la interdependencia; todo aquello en lo cual los seres humanos somos dependientes unos de otros a escala planetaria ${ }^{12}$.

Coincidimos con este pensador en cuanto a la terminología, sin embargo, disentimos en algunos aspectos. Según Muñoz Ledo, la globalidad comenzó a finales del siglo XV y es el germen de la globalización contemporánea. Nosotros consideramos que lo global ha existido siempre -aunque no nos demos cuenta de su presencia- pues tiene un cariz antropológico. Es algo propio de todo ser humano, quien naturalmente pertenece a una familia, colonia, pueblo, nación, continente, mundo. Lo global es entonces pertenencia -reconocida o no, aceptada o no-, relación de cada persona con su entorno físico y humano ${ }^{13}$.

De acuerdo con los términos que hemos definido, es posible distinguir entre lo global y la globalización. Lo global viene dado, la globalización requiere de cierta intencionalidad. Actualmente, la densidad poblacional y los medios de comunicación de una u otra manera nos han globalizado. Hay procesos

\footnotetext{
${ }^{12}$ En: CORREA Eugenia, et al., Globalidad, crisis y reforma monetaria., p.5.

${ }^{13}$ Habría que leer cuidadosamente los prolíficos textos sobre el tema, pues en ocasiones identifican los términos. Algunos autores llaman global a lo que nosotros entendemos aquí como globalización, o bien, en la globalización incluyen lo global.
} 
de sensibilización, de hacinamiento que se han visto favorecidos por la eficacia de estos medios. El impacto de la globalizacion nos lleva a una toma de conciencia sobre lo global, a poner en acto lo que en ocasiones se encuentra en vida latente. Es entonces cuando existe el riesgo de perder la identidad y de que el proceso se revierta en contra del ser humano.

Un hecho histórico que resulta ilustrativo es el de las comunidades castellanas del siglo XVI. En los moradores de estas regiones -por un sentido de identidad y de pertenenciaafloraba lo global: defendían su lengua y sus tradiciones. Pero rechazaban la globalización: no deseaban internacionalizarse, por eso no querían que los gobernaran autoridades extranjeras impuestas por Carlos $\mathrm{V}^{14}$.

CELAG ${ }^{15}$ divide los temas de lo global en los siguientes apartados:

- La gobernabilidad mundial. Los fenómenos políticos asociados a la globalidad y las instituciones que hacen posible dirigir esos procesos.

- La sostenibilidad del desarrollo. El conjunto de problemas de la interdependencia, la erosión de la corteza terrestre, la desertificación, el agotamiento de los recursos no renovables, la relación demografía-economía mundial.

- Los derechos humanos. Los problemas de la mujer, de los jóvenes. La cultura y las modificaciones de la convivencia humana derivadas del fenómeno global.

- La integración regional. La respuesta de las naciones y los grupos de naciones a la globalidad. La formación de bloques y las posturas económicas. Los efectos del conocimiento, la educación, la ciencia y la tecnología, en las relaciones humanas.

- El análisis local y sectorial. Medición de los efectos y de las relaciones entre la aldea global y la aldea local.

${ }^{14}$ Cfr. CRUZ DE GALINDO, Luz María., "Los comuneros: un apunte histórico", en Revista Arbor., Tomo CLXV., p.731.

${ }^{15}$ Cfr. MUÑOZ LEDO, P., en op.cit., pp.6-7. 
Por otro lado, los temas de la globalización pueden variar de acuerdo con el momento histórico. En la actualidad son ${ }^{16}$ : - El peso del Norte frente al Sur. La desigualdad por los privilegios de los países ricos en detrimento de los pobres.

- Tendencia al pensamiento único. Nuevas formas de totalitarismo económico, político y social. Disminución del poder de tomar decisiones de los Estados y comunidades locales. Control social a través de los medios de comunicación.

- Influencia de la cultura posmoderna. Nuevos enfoques respecto a la salud, las condiciones laborales, la democracia y la soberanía.

La realidad de lo global y de la globalización en nuestros días es, por ejemplo, el hecho de que seis países europeos, con una personalidad innegable -Dinamarca, Estonia, Alemania, Irlanda, Países Bajos y España-, se han convertido en socios abiertos a la solución de problemas globales; se encuentran unidos para la investigación de los procesos de desarrollo y sus resultados ${ }^{17}$. Los tópicos son muy diversos: ámbito privado, desarrollo comunitario, discapacitados, aprendizaje a lo largo de la vida...

Entre otras conclusiones, afirman que la nueva economía -como un fenómeno propio de la globalización- no provoca necesariamente personas buenas o malas, pero sí incluidos o excluidos. Nosotros pensamos que esto, a la larga, sí puede influir en la conducta moral, y por eso la economía ha de promover la presencia de societarios, y de una repartición de la riqueza más equitativa.

Los seis socios están preocupados por las marcadas diferencias en los niveles y calidad de vida de los países de la comunidad internacional. Diferencias que tienden a persistir debido a la dinámica de los sistemas económicos en bloques, relacionados entre sí por el comercio y por la internacionalización del capital.

\footnotetext{
${ }^{16}$ Cfr. ARANGUREN GONZALO, Luis A., "Ser solidario, más que una moda", en Revista La cuestión social., Año 7., No.4., p.350.

${ }^{17} \mathrm{Cfr}$ : http://www.copenhagencentre.org/TCCWEB/TCCWeb.nsf/UNGLOBAL/unglobalcompact.org (2001).
} 
A finales del siglo XX los avances de la ciencia y la tecnología permiten conocer, en cuestión de minutos, los problemas de cualquier parte del mundo. También se propagan, aún en forma involuntaria, las consecuencias de las medidas de política económica que se concentran en contados círculos de poder y toma de decisiones. Por lo tanto, es prácticamente imposible esperar un cambio racional en las estructuras y corrientes de la economía globalizada, si no ocurre un cambio concomitante en la correlación de fuerzas del poder político en el nivel internacional.

Los seis países insisten en que el orden al que aspiran parte de reconocer que el hombre tiene una identidad de especie. Esto los estimula para actuar con solidaridad hacia su condición humana ${ }^{18}$.

\section{¿GLOBALIZACIÓN VS. IDENTIDAD?}

Pensamos que los límites entre la globalidad y la globalización son intangibles, y que todos -de una u otra manera-formamos parte de ambos. Pero globalizados o no, si dentro de un mundo tan plural, día con día encontramos en nuestra familia vínculos personalizantes que nos recuerden quiénes somos, de dónde venimos y a dónde vamos, será más fácil conservar nuestra identidad y la capacidad de participar, sin masificarnos.

El fenómeno de la globalización ha sido estudiado por innumerables pensadores. Por ejemplo, el sociólogo estadounidense Daniel Bell ${ }^{19}$ dice que han surgido, a lo largo y ancho del mundo, nuevas infraestructuras en las comunicaciones (y esto obviamente favorece el hecho que ahora nos ocupa). La infraestructura anterior, animada por la Revolución Industrial, fue el transporte; las de la sociedad posindustrial son el cable, la banda de amplia frecuencia, la televisión digital, la fibra

${ }^{18}$ Cfr. MARTíNEZ, Ifigenia., "Reforma del sistema monetario internacional ante la globalidad", en CORREA, Eugenia, et al., op.cit., p.213.

${ }^{19}$ Cfr. "Internet y la nueva tecnología”, en Letras Libres., Año II., No.13., p.56. 
óptica, el fax y el correo electrónico, entre otras. Hoy la Internet y la red mundial (World Wide Web) han crecido en menos de cinco años a un ritmo sin precedentes en la historia de las comunicaciones. Bell insiste en que ningún adelanto previo había invadido tan rápidamente las conciencias y asegurado tan amplia acogida pública.

Por su parte, el candiense Marshall McLughan previó que para finales del siglo XX aparecería la aldea global, representada por los poderes político y económico ${ }^{20}$. Esto se ha producido pero con ciertos bemoles. El acceso a los beneficios de la globalización es un privilegio restringido; el contenido de las comunicaciones no siempre corresponde a la realidad y la unidad política: más que conseguirse, en ocasiones se ha fragmentado. Esto nos hace ver que de una u otra manera siempre existirá lo regional, en mayor o menor grado.

McLughan previó una aldea donde se borraban fronteras, gobiernos y tradiciones para adquirir una civilización y una cultura uniforme y mundial. Consideramos que una idea así suprimiría la identidad de los pueblos.

En 1998, Alain Touraine habló de una interdependencia de los pueblos. Pensamos que la postura de Touraine defiende tradiciones y culturas donde se participan los valores de cada grupo, para beneficio de la comunidad mundial. Este sociólogo inclina la balanza a la conservación de la personalidad de cada región, y por tanto defiende la identidad. Desde nuestro punto de vista, la globalización puede ser benéfica si respeta la soberanía de los pueblos, y ellos mismos deciden cómo participan con otros y qué admiten de los demás.

Los distintos enfoques y la complejidad del fenómeno de la globalización se expresan también en los siguientes puntos de vista:

Pierre Hassner ${ }^{21}$, profesor del Centro de Estudios de Investigación Internacional en París, señala que es fundamental el

\footnotetext{
${ }^{20}$ Apud GÓMEZ ANTÓN, Francisco., "Un mundo cambiante como marco de la acción educativa", en Lo permanente y lo cambiante en la educación., p.36. ${ }^{21} \mathrm{Cfr}$. "El orden global en el siglo XXI", en Letras Libres., Año II., No.13., pp.18-23.
} 
asunto de la identidad, individual o colectiva. Hassner habla del cambio y la continuidad, de lo global y lo particular. El problema es que las identidades supuestamente deben creerse o sentirse como algo natural, pero ahora, en nuestra era posmoderna todo mundo sabe que son artificiales [sic]. Las grandes ideologías están muertas [sic], de modo que sólo queda una lucha entre la tecnocracia y el populismo. Para cumplir de manera eficiente, la tecnocracia invita a la integración europea, a la existencia de la moneda única y a la globalización. Hoy lo particular, lo local y lo nacional coexisten con lo universal y lo global. Hay un problema con las instituciones que deberían mediar entre los dos niveles, tal vez esto explique la falta de participación política. La poca concurrencia electoral de los norteamericanos y su negativa a morir por la patria son indicios de mala salud. Hay que desinventar al individuo egoísta incapaz de sacrificarse por una causa colectiva, el hombre que sólo busca el bienestar material, que no tiene interés en el sacrificio ni en la grandeza.

Robert Cooper ${ }^{22}$, director de la Región Asia-Pacífico en el Ministerio del Exterior del gobierno norteamericano, dice que conforme una sociedad es más educada, la identidad de las personas también es más compleja. Explica las guerras de soberanía del consumidor por la presencia de consumidores con una identidad débil, en vez de ciudadanos con identidad fuerte. Para él la pregunta clave es si el nuevo consenso liberal -la democracia, el imperio de la ley y la cooperación internacional- se aplicará en todas partes o si seguirá siendo algo específico de Occidente. En Europa hay gran cantidad de Estados que quieren limitar su propia soberanía vinculándose a la Unión Europea, pero el resto del mundo todavía tiene sentimientos ambivalentes hacia estos nuevos valores.

Por su parte Edward Luttwak ${ }^{23}$, profesor en el Centro para Estudios Estratégicos e Internacionales en Washington, afirma

${ }^{22}$ Cfr. Ibídem.

${ }^{23}$ Cfr. Idem. 
que ahora las premisas liberales alcanzan una gran proyección, quizá no en el mundo islámico, pero sí en toda América Latina, con las posibles excepciones de Colombia y Haití.

Timothy Garton Ash ${ }^{24}$, catedrático en St. Anthony's College en Oxford, señala que una de las ironías de la Europa contemporánea es que, en el mapa europeo, hay más naciones que nunca en su historia. Si comparamos el mapa de 1999 con el de 1899, encontramos por lo menos a quince recién llegados. Tal vez sean Estados menos efectivos, pero allí están y su existencia sirve de antídoto contra las afirmaciones más simplistas de la teoría de la globalización en el sentido de que el Estado va a desaparecer. La gente todavía ve en esta institución su núcleo principal de identidad y su prospecto de autogobierno democrático. Si contamos las estructuras políticas que rigen o complementan a una economía globalizada, entonces debemos abordar los temas de identidad o democracia, internacional o estatal. Quizá la Unión Europea representa lo más lejano a lo que hemos llegado en la construcción de una identidad y una democracia parciales de un tipo significativo y durable, a un nivel distinto al del Estado nacional.

Garton insiste: "Soy un liberal universalista. Creo en un núcleo de valores comunes a la bumanidad. Y creo que la globalización, y en particular la revolución en las comunicaciones, nos da una oportunidad extraordinaria de diseminarlos".

Eric Hobsbawm ${ }^{25}$, profesor emérito de Historia Económica y Social en la Universidad de Birbeck, habla de una tendencia incuestionable hacia la globalización de la economía, y aun de la cultura, pero según él, no existe una tendencia equivalente que globalice a las instituciones políticas o de otro tipo. Esto significa que en el futuro inmediato todavía viviremos una era en donde las fuerzas de la globalización

\footnotetext{
${ }^{24}$ Cfr. Idem.

${ }^{25}$ Cfr. Idem.
} 
deben coexistir y negociar con los Estados-nación, que siguen siendo los únicos centros de autoridad política real, aun si es bastante reducido el número de naciones-Estado que cuentan en este tema de la negociación global.

Pese a las variadas perspectivas de estos intelectuales, existen aspectos comunes que preocupan a todos: la actitud de las naciones frente al fenómeno de la globalización; el interés por analizar los tipos de identidad y el significado tan complejo del concepto; la relación entre lo global y lo particular, y entre lo internacional, nacional y regional; la necesidad de instituciones adecuadas que regulen esta relación, así como de estructuras políticas que rijan los aspectos socioeconómicos, culturales, etcétera. La presencia de ideologías que dan el tono a la globalización, el modo de valorarlas y la insistencia de algunos de que estas ideologías han desaparecido. Un pensador habla de la paradoja de la presencia de nuevas naciones en un mundo que pretende ser global, e insiste en que es una afirmación simplista decir que el Estado va a desaparecer. De hecho, todavía para muchas personas esta institución es el elemento que conserva la identidad y puede dar paso a la democracia.

Pensamos que la globalización y la identidad no necesariamente son antagónicas y que siempre coexistirá lo particular con lo global, pues la razón de ello es antropológica. En el ser humano siempre se dará el binomio intimidad-apertura. El problema es encontrar el punto de equilibrio, sin polarizarse. Consideramos que, sin duda, en la globalización existe una influencia ideológica manifiesta u oculta, la cual se expresa en diversas actitudes. 


\section{LA GLOBALIZACIÓN Y ALGUNAS DE SUS CONSECUENCIAS}

\begin{tabular}{|c|c|c|c|}
\hline Ámbito & Hechos & Lo positivo & Lo negativo \\
\hline Tecnológico & $\begin{array}{l}\text { Irrupción de } \\
\text { la cibernética. }\end{array}$ & $\begin{array}{l}\text { Interdependencia } \\
\text { comunicativa } \\
\text { a velocidad } \\
\text { vertiginosa. }\end{array}$ & $\begin{array}{l}\text { Innumerables ex- } \\
\text { cluidos, cada vez } \\
\text { más rezagados. }\end{array}$ \\
\hline Económico & $\begin{array}{l}\text { Desaparición } \\
\text { de barreras } \\
\text { arancelarias. } \\
\text { Derrama } \\
\text { económica } \\
\text { desigual en las } \\
\text { distintas regiones. }\end{array}$ & $\begin{array}{l}\text { Posibilidad de } \\
\text { acceder a cualquier } \\
\text { bien. } \\
\text { Necesidad de } \\
\text { optimizar los } \\
\text { productos. }\end{array}$ & $\begin{array}{l}\text { Competitividad } \\
\text { inhumana. } \\
\text { Desigualdad } \\
\text { de comunidades } \\
\text { con distinta } \\
\text { capacidad } \\
\text { económica. } \\
\text { Adopción de } \\
\text { necesidades } \\
\text { artificiales. }\end{array}$ \\
\hline Político & $\begin{array}{l}\text { Desdibujamiento } \\
\text { de fronteras. }\end{array}$ & $\begin{array}{l}\text { Integración de } \\
\text { las personas } \\
\text { como societarios } \\
\text { del mundo. } \\
\text { Defensa de los } \\
\text { valores universales. }\end{array}$ & $\begin{array}{l}\text { Pérdida de } \\
\text { identidad nacional. } \\
\text { Totalitarismo } \\
\text { disfrazado } \\
\text { de igualitarismo. }\end{array}$ \\
\hline Cultural & $\begin{array}{l}\text { Convivencia } \\
\text { de etnias. } \\
\text { Diversidad de } \\
\text { credos religiosos. } \\
\text { Libre expresión } \\
\text { de ideas políticas. }\end{array}$ & $\begin{array}{l}\text { Virtual acceso a las } \\
\text { mismas oportunidades. } \\
\text { Tolerancia. } \\
\text { Diálogo democrático. } \\
\text { Comunitarismo. } \\
\text { Superación de } \\
\text { antagonismos. }\end{array}$ & $\begin{array}{l}\text { Racismo } \\
\text { enmascarado. } \\
\text { Mimetismo. } \\
\text { Eclecticismo. } \\
\text { Controversias } \\
\text { prolongadas e } \\
\text { irresolutas. } \\
\text { Neoliberalismo. } \\
\text { Radicalismos } \\
\text { ideológicos. }\end{array}$ \\
\hline
\end{tabular}




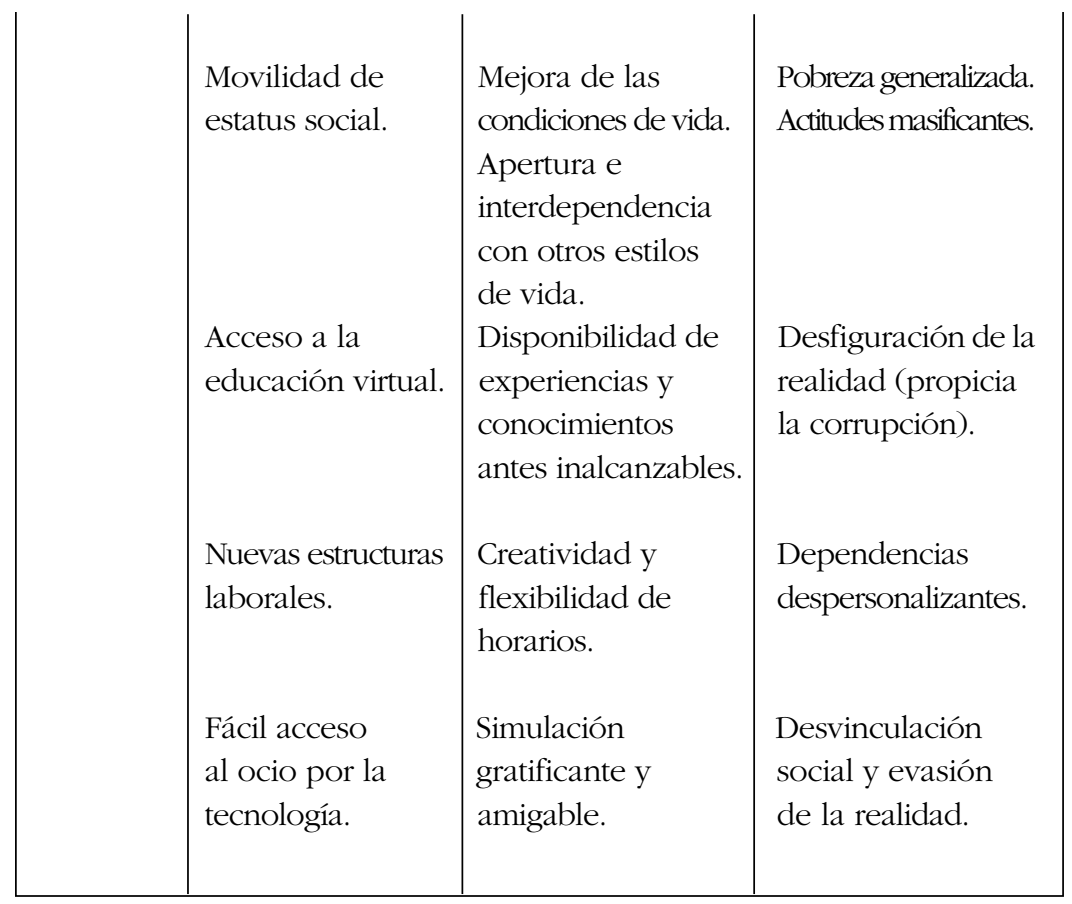

Los datos que hemos presentado manifiestan la importancia de que los responsables de encauzar el avance de la globalización posean principios éticos. Los acontecimientos favorecen la auténtica promoción humana y comunitaria sólo si se respetan los inalienables derechos de las personas y se procuran ámbitos de convivencia en la libertad, la justicia y la solidaridad.

Es evidente que, por la globalización, los miembros de una sociedad pertenecen, cada vez más, a diferentes grupos, y dentro de ellos desempeñan gran variedad de roles según su estatus, prestigio, capacidad personal, etcétera. La pluralidad de grupos requiere de dirigentes que, en distintos grados y niveles, regulen las interrelaciones humanas. La autoridad bien 
ejercida favorece al orden social, lo conserva y perfecciona. De esta manera encauza adecuadamente la convivencia.

Por el alcance de tales dirigentes, su actividad no puede improvisarse; se ha de regir por normas que garanticen la rectitud moral y la eficacia de sus actos. Frente a los graves problemas de desarrollo que se dan en los países del tercer mundo y ante la experiencia deshumanizante del progreso económico de los países desarrollados, exhibida en sus aspectos más dramáticos, aparece una nueva ciencia, la de la dirección social nacional e internacional. Esta ciencia puede ser de gran valor para orientar a quienes, como dirigentes, tienen la responsabilidad de participar en la orientación de la vida social en un futuro inmediato. Se trata de una disciplina práctica, normativa, cuyo fin es orientar la conducta de las autoridades en sus tareas directivas ${ }^{26}$.

Isaac Guzmán Valdivia señala tres normas fundamentales para una dirección social eficaz ${ }^{27}$ :

1. Tener contacto con la realidad histórico-cultural de grupos y comunidades.

2. Respetar la naturaleza de personas y sociedades.

3. Apegarse al deber ser de la vida social.

Hablamos entonces de la prudencia -que apoyada en la veracidad y en la justicia- regula las tareas del dirigente para encauzar la acción comunitaria. La familia, como primera escuela de virtudes sociales, ha de ser la cuna de esos dirigentes.

\section{VÍAS PARA COMBINAR LA IDENTIDAD FAMILIAR CON LA APERTURA A LA GLOBALIZACIÓN}

Nuestra inquietud es potenciar las actividades familiares cotidianas, aparentemente intrascendentes, para darles sentido y proyección; descubrir lo relevante del quehacer de todos los días y su influencia en los demás ámbitos.

${ }^{26}$ Cfr. GUZMÁN VALDIVIA, Isaac., Humanismo trascendental y desarrollo., p.161.

${ }^{27}$ Cfr. Ibidem., p.161 y ss. 
Creemos que el núcleo de la realidad global es la familia y lo que ahí pase incidirá -en forma de círculos concéntricosen la vida escolar, laboral, recreativa, comunitaria. Lo importante es focalizar actividades que muchas veces pasan inadvertidas, pero que son muy trascendentes, y proyectarlas extra-familiarmente.

La tarea de la familia es fomentar la identidad del grupo y la apertura a la globalización, preparar a sus miembros para dar una respuesta -ética y coherente- a los fenómenos actuales. Esto puede hacerse, por ejemplo, en una conversación de sobremesa, mediante la orientación informal a la actividad profesional de los hijos, con el intercambio de criterios sobre los acontecimientos locales y mundiales, y la recomendación de textos que amplíen tales criterios.

Para fines didácticos, hablaremos de las responsabilidades familiares en torno a lo global y a la globalización, respectivamente.

Frente a lo global la familia ha de:

1. Reconocer y aceptar las modificaciones de la convivencia, derivadas de la ineludible realidad de este fenómeno. Un buen principio es tener capacidad de observación para detectar los cambios en la estructura y dinámica familiar, a lo largo de la existencia de los seres que la constituyen. Después, trasladar esta capacidad a la vida comunitaria para advertir cambios significativos. La aceptación depende de los principios que inspira la conducta personal. Es perfectamente válido y un signo de madurez y coherencia, rechazar lo que produce un daño moral. Este reconocimiento y aceptación de lo global no tiene por qué ser sinónimo de despersonalización.

2. Propiciar el diálogo entre sus integrantes, pero sin enquistamientos. Existe el riesgo de que un clima muy agradable dentro del núcleo familiar produzca un efecto secundario negativo: que las personas no incursionen más allá, ni se interesen en lo que sale de su reducido entorno. Por eso 
los padres han de estar alertas y no sobreproteger ni absorber a sus hijos, hay que convertirlos en ciudadanos del mundo y evitar que sean desadaptados o egoístas. Esto facilitará la vinculación de las personas de una colonia o comunidad, con grupos mayores, nacionales e internacionales, para formar círculos concéntricos cada vez más amplios, hasta llegar a la comunidad de las naciones. En esta última también se ha de dar el diálogo cuyo fin sea procurar una integración regional sin exclusión, pero respetando las identidades nacionales. Es importante evitar que principios éticos provoquen pugnas culturales. A escala personal hace falta ser fiel a uno mismo y poseer un fuerte sentido de compromiso para conservar tradiciones, sentimientos de arraigo, etcétera, y a la vez participar en una sociedad globalizada. De lo contrario, puede aparecer la tan indeseable masificación.

3. Tener presente que en la gobernabilidad mundial siempre coexistirá lo global y lo particular y, por tanto, es necesario respetar los derechos humanos. Por eso, desde la familia, conviene hacer ver que cada persona es sujeto de derechos y obligaciones. Esto no siempre se aprecia, debido a la cotidianeidad en el trato. Para lograrlo lo primero es saber qué es una buena convivencia en cualquier ámbito, privado o público; aprender a convivir con los más próximos -cónyuges, padres, hermanos y otros parientes- en un entorno de respeto a las naturales peculiaridades. Además ${ }^{28}$ desde la familia, a través de la formación de dirigentes sociales, habrá que neutralizar los efectos centrífugos de las diferencias socioculturales que se exacerban en un ambiente político donde se acentúan las diferencias y se rebajan los elementos comunes. Otra tarea del grupo familiar es hacer ver a los hijos que las personas no tienen un único estatus, ni son miembros de una sola comunidad, sino de

${ }^{28}$ Cfr. ETZIONI, Amitai., La nueva regla de oro., p.241. 
muchas que se superponen y entrecruzan. Esto les ayudará a entender las legítimas diferencias y a no cometer la enorme injusticia de tratar igual a los diferentes.

4. Considerar la estructuración de nuevos bloques ante las culturas económicas. Las necesidades económicas y su adecuada satisfacción son un aspecto fundamental en las relaciones humanas. Se trata de intereses que pueden originar serios conflictos inter y extra nacionales. Por eso se hace imperativo promover un espíritu de reconciliación ${ }^{29}$, sobre todo si no ha estado presente desde el principio. Esta actitud es una de las menos estudiadas, pese a su importancia dentro de las sociedades comunitarias. No debe confundirse con la mediación, la resolución de conflictos o la negociación: cada uno de esos aspectos está muy ligado a los intereses distintos de las partes. La reconciliación surge de lo más íntimo de cada persona, tiene que ver con elementos afectivos como el resentimiento y el odio, y se asocia a estados psicológicos. Por todo ello, el núcleo familiar es el hábitat más adecuado para formar en esta actitud que no siempre se da espontáneamente, y los padres han de estar muy atentos para cultivarla.

5. Adoptar los avances culturales y sus efectos en el conocimiento y la educación. En lo posible, la familia ha de mantener un estrecho contacto con los adelantos tecnológicos, los descubrimientos científicos y las aportaciones artísticas que enriquecen a la cultura, con el fin de mejorar los estilos y la calidad de vida. También necesita darse cuenta de que algunos adelantos, aunque aparentemente representan beneficios a la humanidad, muchas veces encubren falacias que sólo favorecen a algunos oportunistas. Por eso, hay que evaluar las novedades, respetar y adoptar lo valioso de las distintas culturas y combatir lo que suponga deterioro humano.

${ }^{29}$ Cfr. ETZIONI, Amitai., op.cit., p.244. 
6. Equilibrar y dar sostenibilidad al desarrollo no sólo económico, también sociocultural. Para ello la familia -insertada en la sociedad global- no puede ignorar los problemas de la mujer; de los niños, jóvenes y personas de la tercera edad; de quienes tienen capacidades diferentes; inmigrantes, etcétera. En su preocupación por ofrecer a la sociedad miembros participativos, ha de sembrar en ellos la familiaridad con el colectivo y la inquietud por promover un cambio social que favorezca el bien general. Esto se relaciona directamente con las expectativas sobre la colaboración, la apertura ante las conductas de los demás, sean esperadas o desconcertantes, y el costo de la participación social.

7. Evaluar, desde la familia, los efectos de las aldeas locales y globales. Los padres han de procurar medir el grado de propiedad, idoneidad, efectividad y eficiencia -en relación con el desarrollo humano- de una aldea con determinadas características. Esto puede hacerse desde distintas perspectivas -número de personas, interacciones, ubicación, recursos materiales y humanos, comercialización de productos, aprendizajes significativos-y permite la toma de decisiones en la vida familiar. Es importante tener ciertos parámetros para medir los efectos de la dinámica social y tratar de hacer más eficientes los esfuerzos humanos y el aprovechamiento de los recursos. Por ejemplo, la inserción en lo global puede facilitar la productividad al permitir la distribución más adecuada del trabajo, por contar con una más amplia gama de recursos e intercambio de experiencias. Lo regional, y concretamente lo familiar, preserva del anonimato y del gregarismo y puede fomentar el sentido de identidad y de pertenencia que da seguridad y confianza.

Ante la globalización, la familia ha de:

1. Estar informada -aunque sea someramente- de las diferencias Norte-Sur y tratar de descubrir sus verdaderas causas, a saber: la falta de equilibrio en las oportunidades, el mal aprovechamiento de recursos materiales y humanos, el 
abuso de los más fuertes hacia los débiles. Dentro de la vida familiar se ha de tener la mentalidad de fortalecer a los débiles, y de evitar los mimetismos degradantes que se originan al asumir estilos de vida sin ningún criterio, sólo por ser el prototipo de países aparentemente más desarrollados.

2. Evitar dogmatismos y la imposición de un pensamiento único. Esto para no caer en el sometimiento totalitario de las naciones fuertes, ni dejarse influir por algunos planteamientos posmodernos que exacerban el sentimentalismo en detrimento de la racionalidad. Dentro del seno familiar y después en la vida social es necesario admitir las diferentes identidades para responder adecuadamente a los nuevos enfoques sobre la salud, condiciones laborales, democracia y soberanía. Por ejemplo, los hijos deben saber que, frente a las demandas laborales competitivas, no es ético atropellar a otro para subir en el escalafón; ante el desmedido afán de novedades, es necesario evitar el consumismo y vivir la sobriedad; contra la manipulación genética se requieren argumentos sólidos para la defensa de la vida...

3. Promover una educación enriquecedora con el fin de mantener el equilibrio entre identidad y globalización. Padres e hijos han de procurar asumir una lealtad estratificada ${ }^{30}$ que no olvide el compromiso con la comunidad propia inmediata y con la comunidad global. Se han de establecer prioridades según los problemas y carencias. Esto es más fácil cuando los miembros de la comunidad tienen sentido de pertenencia no sólo a su entorno más próximo, sino también a globalidades más extensas. Así, para que la comunidad de comunidades se sostenga, los miembros que la constituyen han de combinar su apreciación de y su compromiso con sus propias tradiciones, culturas y valores particulares, con el respeto a las tradiciones, culturas y valores de otros grupos. No hay prueba o razón sociológica para

${ }^{30}$ Cfr. Ibídem., pp.238-241. 
pensar que el compromiso con la propia cultura sea antitético respecto a conocer y respetar los ajenos. Además, centrarse exclusivamente en la cultura propia, obstaculiza las comunicaciones y la compresión intercultural.

Frente a las ineludibles consecuencias de lo global y de la globalización, la familia -inmersa en un ambiente al que tiene que reorientar- debe asumir el protagonismo que le demandan los signos de los tiempos, y que sin variar en lo esencial, tiene los rasgos y las características de los que hemos hablado. 
AAVV., "El orden global en el siglo XXI"., Letras Libres., Año II., No.13., enero de 1999., México.

AAVV., Lo permanente y lo cambiante en la educación., Pamplona., Ediciones Universidad de Navarra S.A., 1991.

ARANGUREN GONZALO, Luis A., "Ser solidario, más que una moda"., Revista La cuestión social., México., Año 7., No.4., invierno de 1999-2000.

BELL, Daniel., "Internet y la nueva tecnología”, Letras Libres., México., Año II., No. 13., enero de 1999.

CORREA, Eugenia; GIRÓN, Alicia; MARTÍNEZ, Ifigenia (compiladoras)., Globalidad, crisis y reforma monetaria., México., UNAM., Instituto de Investigaciones Económicas., 1999.

CRUZ DE GALINDO, Luz María., “Los comuneros: un apunte histórico”., Revista Arbor., México., Tomo CLXV., No.652., abril de 2000.

Enciclopedia ${ }^{\circledR}$ Microsoft ${ }^{\circledR}$ Encarta 2001

ETZIONI, Amitai., La nueva regla de oro., Barcelona., Ediciones Paidós Ibérica., 1999.

OTERO OLIVEROS, F., ¿Qué es la orientación familiar?., Pamplona., Ediciones Universidad de Navarra, S.A., 1992.

GARCÍA HOZ, Víctor (compilador)., La educación personalizada en la familia., Madrid., Ediciones Rialp, S.A., 1990.

GUZMÁN, VALDIVIA, Isaac., Humanismo trascendental y desarrollo., México., Editorial Jus., 1985.

MÁRQUEZ PIÑERO, Rafael., Derecho penal y globalización., México., Editorial Porrúa., 2001.

MESSNER, Johannes., La cuestión social., Madrid., Ediciones Rialp, S.A., 2ª edición., 1976.

PÉREZ ADÁN, José., Sociología., Pamplona., Ediciones Universidad de Navarra, S.A., 1997.

www.copenhagencentre.org/TCCWEB/TCCWeb.nsf/ UNGLOBAL/unglobalcompact.org. (2001).

VALLET DE GOYTISOLO, Juan., Sociedad de masas y derecho., Madrid., Taurus Ediciones, S.A., 1969. 